\title{
AGE-ADJUSTED MORTALITY RATES OF NEOPLASTIC AND CIRCULATORY DISEASES AND THEIR DEMOGRAPHIC FACTORS IN SLOVAK REGIONS DURING 1996-2013
}

\author{
Daniel Pella ${ }^{1}$, Ján Fedačko ${ }^{1}$, Rastislav Rajnoha ${ }^{2}$, Beáta Gavurováa Samuel Koróny ${ }^{4}$ \\ ${ }^{1} 1$ st Department of Internal Medicine, Louis Pasteur University Hospital, Pavol Jozef Šafárik University in Košice, Košice, Slovak Republic \\ ${ }^{2}$ Faculty of Management and Economics, Tomas Bata University in Zlín, Zlin, Czech Republic \\ ${ }^{3}$ Faculty of Economics, Technical University of Košice, Košice, Slovak Republic \\ ${ }^{4}$ Research and Innovation Centre, Faculty of Economics, Matej Bel University, Banská Bystrica, Slovak Republic
}

\begin{abstract}
SUMMARY
Aim: Knowledge of the causes of deaths in Slovakia is lacking. This is significant because diet and lifestyle factors are different in central Europe compared to Western, Northern and Southern Europe. This study aims to discern trends of age-adjusted mortality rates caused by various diseases in relation to demographic factors.

The aim of our study was to find certain statistical aspects including trends of age-adjusted mortality rates caused by neoplastic (Chapter II) and circulatory diseases (Chapter IX) in the Slovak population in relation to available demographic factors (sex, region and calendar year of death).

Methods: Dataset of individual deaths in Slovakia with certain demographic factors (sex, region and calendar year of death) during 1996-2013 were provided by the Slovak National Center of Health Informatics. Regression and correlation analyses and analyses of variance and of covariance were used to yield the level of significance.

Results: We found significant differences of age-adjusted mortality rates between men and women, between Chapter II and Chapter IX and among Slovak regions. Age-adjusted mortality rates decline significantly in most regions for both sexes with the exception of stagnation in four regions in a group of Chapter II women (Košice, Nitra, Trenčín and Žilina) and one region in Chapter IX, also in group of women (Žilina).

Conclusions: Mortalities caused either by Chapter II or Chapter IX diseases are significantly dependent on chapter, sex and region with mortalities either declining or stagnating.
\end{abstract}

Key words: mortality, diseases of the circulatory system, neoplasms, statistical data analysis

Address for correspondence: J. Fedačko, 1st Department of Internal Medicine, Louis Pasteur University Hospital, Pavol Jozef Šafárik University in Košice, Trieda SNP 1, 04190 Košice, Slovak Republic. E-mail: jan.fedacko@upjs.sk

https://doi.org/10.21101/cejph.a5056

\section{INTRODUCTION}

Mortality is a reliable picture of public health (1). It's also the most accurate way to measure health (2). It is generally believed that the most important causes of death also have the sharpest social slope (3). The basic prerequisite for research of disparities in mortality is that the disparity results from social assumptions that are not biologically set (4). Although it cannot be ruled out that social differences in mortality could have a biological foundation, they are developing through social mechanisms and social environment. Socioeconomic differences in mortality were historically the lowest in the Netherlands, Denmark, Norway and Sweden. The greatest differences in mortality were in France, Italy, the US and Finland. Despite the very high level of social inequality in the US, this country does not have higher differences in mortality compared to the countries where this disparity was minimal (5). According to the results of several research studies, on average, women have worse health than men, though expectations of higher life expectancy of women are higher among women (6-8). Some experts point to the importance of social differences between men and their impact on mortality $(9,10)$, while Klein (11) indicates that in the lowest social class, there are no gender differences in mortality. Reasons of physical handicaps of women are not known yet. As the main biological differences are set - different physical conditions and health and mortality trajectories $(12,13)$. In general, women exhibit better health behaviour (14). The differences in mortality between the sexes arise from the interplay of physiological, psychological and behavioural differences. Klein (11) in his study reported that higher mortality in men is due to different physical structure than women and more stressful role in society. Bassuk et al. (15) reported that in men education, income and occupational prestige are significant predictors of mortality, while women only the income has a particularly important role. Lampert (16) in his research studies found that gender differences between the sexes can be seen also at work, health status and health behaviour. Health behaviour, attitudes, habits and 
etc. are connected to the material sources of an individual. The most commonly examined factors of health behaviour studied in epidemiology include smoking, alcohol consumption, obesity and physical activity. Some psychosocial factors used in the literature as a relative social status, integration, stress and etc. are difficult to measure and have complex concepts explaining their impact on mortality. It also causes problems with the unification of the results from these trials. Beckett (17) argues that social support and stress factors are more important determinants of health than traditional risk factors (smoking, alcohol consumption, physical activity). These factors create a relationship between socioeconomic status, health and mortality (18).

These mentioned research studies confirm significant heterogeneity in the results, as well as the complexity in explicitly defining the trajectories of the impact of various factors on mortality. This is due to different target orientation of many research teams' research studies in pursuit of psychological, social, economic, medical aspects in the development of mortality. Much more clearly can be seen the results of research studies when examining the impact of gender and age, as core variables affecting differences in mortality of individual groups of diseases. When examining mortality from cardiovascular disease, numerous research teams link the gender difference in mortality with socio-economic status (19-21) or concentrate on major risk factors (22-24).

It is well known fact that more than three fourths of deaths in Slovakia are caused by diseases from Chapter II (neoplasms, C00D48, ICD - International Statistical Classification of Diseases and Related Health Problems) or from Chapter IX (circulatory system diseases I00-I99). The corresponding proportions during 1996-2013 were $22.7 \%$ and $54.0 \%$ (together $76.7 \%$ ). Overall absolute number of deaths caused by neoplastic diseases or by circulatory diseases was 764,402 (228,009+536,393). Main objective of our paper is to find some statistical aspects including trends of age-adjusted mortality rates of neoplastic and circulatory diseases per 100,000 persons of Slovak population in relation with available demographic factors (chapter of ICD, sex, region and calendar year of death).

\section{MATERIALS AND METHODS}

Slovak National Center of Health Informatics offered us data about individual cases of deaths in Slovakia with some demographic (or socioeconomic) factors during 1996-2013. Individual cases were aggregated to obtain overall counts of deaths in corresponding ICD chapter, sex, region and calendar year of death. For purpose of comparisons the counts were adjusted by direct standardisation to age-adjusted mortality rates according to age and to sex. Reference population was EU population in standard 5-year age intervals for both sexes.

Age-adjusted mortality rates eliminate the difference in mortality rates due to a population's age profile and are comparable across countries and regions and over time. They are calculated by applying the age-specific death rates of one region to the age distribution of a standard population (25). Final values of age-adjusted mortality rates per 100,000 persons (AAMR) were used for our comparative analyses. However, they should be viewed as relative indexes rather than as actual measures of mortality risk. Synonym for of age-adjusted mortality rate is age-adjusted death rate (26).
Important point is that any adjusted rate, no matter which method of adjustment is used, has meaning only when compared with a similarly adjusted rate. Its value means little itself (27).

Beside basic descriptive statistics we used regression and correlation analyses and analysis of variance (ANOVA) and analysis of covariance (ANCOVA). Regression and correlation analyses were used for trend estimations of age-adjusted mortality rates per 100,000 persons for separate regions during 1996-2013. Analysis of covariance was used for comparisons based on three categorical factors (chapter, sex and region) and one continuous variable (calendar year of death). We have found ANCOVA useful in testing of regression (slope) parameters equality. The testing can be done also by regression analysis with dummy variables but it is rather slow and complicated approach. That is why we used ANCOVA. One of assumption of ANOVA or ANCOVA is homogeneity of variances in compared groups (tested by Levene homogeneity-of-variance test).

In our case it is not fulfilled. Because of non-homogeneity of variances, we used nonparametric Kruskal-Wallis test with stepwise stepdown multiple comparisons for attainment of homogenous subgroups (IBM SPSS). Another assumption is that each group is an independent random sample from a normal population. ANOVA is robust to departures from normality but the data should be symmetric. An assumption underlying the correct usage of ANCOVA is that the regression slopes associated with the categorical factors are equal (28). As we shall show later in our case this assumption is mostly violated. Luckily in our case it is the most common and least serious problem. Adjusted means are different and one group is above the other group regardless of the level of calendar year. But corresponding trend linear regression lines do not intersect.

\section{RESULTS}

Table 1 shows the basic statistical parameters of age-adjusted mortality rates per 100,000 persons of EU population by sex and region. We can see that both means and standard deviations of AAMR values in group of men are larger in both chapters in comparison with group of women. So spread of data is lager in men group. As we shall see later it is caused mainly by significant declines of AAMR in time. In case of women it is not so often. Our approach was to compare what is comparable (e.g. to compare AAMR of men in one region with AAMR of women in another region is nonsense, ,apples with oranges”). But to compare for example AAMR of men with AAMR of women in the same region is OK. Of course we consider the same ICD chapter in both cases. In tables and in graphs we use common abbreviations of Slovak regions: BC (Banská Bystrica), BL (Bratislava), KE (Košice), NI (Nitra), PV (Prešov), TA(Trnava), TC (Trenčín) and ZA (Žilina).

Histograms in Figure 1 present distributions of age-adjusted mortality rates per 100,000 persons by chapter and by sex. At first sight they seem different between chapters and also between sexes. Later we will show that they are really different.

Possible differences among regions can be presented by error bar plots. Corresponding 95\% confidence intervals of mean are depicted in error bar graphs (Figures 2-5). Let us make some conclusions from them. In Figure 2 it seems that values of age- 
Table 1. Statistical parameters of age-adjusted mortality rates per 100,000 persons by chapter, by sex and by region

\begin{tabular}{|c|c|c|c|c|c|c|c|}
\hline Chapter & Sex & Region & Mean & Median & SD & Minimum & Maximum \\
\hline \multirow{16}{*}{ II } & \multirow{8}{*}{ Men } & $B C$ & 481.3 & 470.5 & 35.26 & 424.2 & 571.4 \\
\hline & & $\mathrm{BL}$ & 454.1 & 446.5 & 34.95 & 385.6 & 529.3 \\
\hline & & KE & 474.4 & 473.9 & 39.34 & 414.2 & 533.5 \\
\hline & & $\mathrm{NI}$ & 512.5 & 505.0 & 34.14 & 464.6 & 586.8 \\
\hline & & PV & 452.6 & 453.3 & 34.21 & 392.4 & 506.6 \\
\hline & & TA & 510.8 & 501.9 & 25.47 & 475.0 & 560.0 \\
\hline & & TC & 448.3 & 447.0 & 31.00 & 395.1 & 527.7 \\
\hline & & ZA & 480.3 & 473.8 & 34.30 & 421.9 & 536.1 \\
\hline & \multirow{8}{*}{ Women } & $\mathrm{BC}$ & 220.3 & 221.1 & 11.96 & 196.7 & 240.0 \\
\hline & & $B L$ & 259.6 & 258.3 & 18.76 & 228.1 & 292.0 \\
\hline & & $\mathrm{KE}$ & 227.4 & 222.6 & 14.97 & 212.9 & 266.5 \\
\hline & & $\mathrm{NI}$ & 249.0 & 251.0 & 13.47 & 220.0 & 267.5 \\
\hline & & PV & 199.2 & 199.1 & 9.45 & 179.0 & 218.1 \\
\hline & & $\mathrm{TA}$ & 249.3 & 246.6 & 16.05 & 225.6 & 287.9 \\
\hline & & TC & 218.5 & 217.1 & 9.23 & 201.6 & 243.0 \\
\hline & & $Z A$ & 223.1 & 222.4 & 10.38 & 199.9 & 239.8 \\
\hline \multirow{16}{*}{ IX } & \multirow{8}{*}{ Men } & $B C$ & $1,243.5$ & $1,283.4$ & 127.09 & 971.9 & $1,442.6$ \\
\hline & & $B \mathrm{~L}$ & $1,010.4$ & $1,036.2$ & 130.93 & 748.8 & $1,238.3$ \\
\hline & & KE & $1,236.2$ & $1,251.0$ & 109.52 & 962.5 & $1,390.9$ \\
\hline & & $\mathrm{NI}$ & $1,193.7$ & $1,205.4$ & 106.32 & 943.9 & $1,333.6$ \\
\hline & & PV & $1,188.9$ & $1,213.6$ & 114.36 & 980.1 & $1,363.1$ \\
\hline & & TA & $1,159.6$ & $1,197.0$ & 121.59 & 885.2 & $1,337.0$ \\
\hline & & $\mathrm{TC}$ & $1,144.3$ & $1,172.8$ & 119.86 & 886.6 & $1,331.0$ \\
\hline & & ZA & $1,150.2$ & $1,161.8$ & 96.87 & 982.2 & $1,381.9$ \\
\hline & \multirow{8}{*}{ Women } & $\mathrm{BC}$ & 902.1 & 931.2 & 86.34 & 703.6 & $1,025.7$ \\
\hline & & $\mathrm{BL}$ & 756.4 & 792.5 & 94.36 & 569.3 & 905.5 \\
\hline & & $\mathrm{KE}$ & 912.1 & 919.0 & 85.72 & 717.8 & $1,019.1$ \\
\hline & & $\mathrm{NI}$ & 880.7 & 899.7 & 67.70 & 768.0 & 982.1 \\
\hline & & PV & 888.1 & 897.4 & 80.74 & 728.0 & $1,011.2$ \\
\hline & & TA & 881.0 & 891.9 & 92.77 & 705.7 & $1,022.0$ \\
\hline & & TC & 840.9 & 861.0 & 73.00 & 688.9 & 975.3 \\
\hline & & ZA & 827.1 & 845.5 & 49.84 & 732.2 & 909.4 \\
\hline
\end{tabular}

adjusted mortality rates per 100,000 persons in regions Bratislava, Prešov and Trenčín are in average smaller (better) than they are in regions Nitra and Trnava for diseases from Chapter II. In case of women the regions - Bratislava, Nitra and Trnava are worse than all other regions.

In diseases from Chapter IX the situation is much different. All regions except Bratislava are roughly on one level. But we need to prove any such differences statistically. It can be done by three-way ANOVA with categorical factors (chapter, sex and region). Homogenous subsets can be found by post hoc tests.

We shall not present all reports of ANOVA and ANCOVA. In Table 2 there is report of testing the null hypothesis that the variance of the dependent variable is equal across groups. The test is significant $(\mathrm{p}<0.001)$. So any statements about differences are questionable. Luckily we can use nonparametric Kruskal-Wallis test which does not require equal variances.

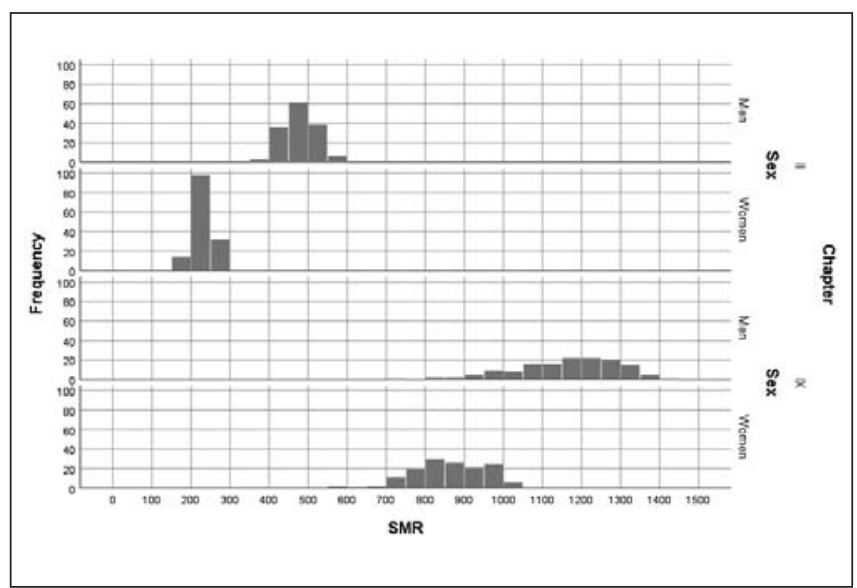

Fig. 1. Histogram of age-adjusted mortality rates per 100,000 persons by chapter and by sex. 


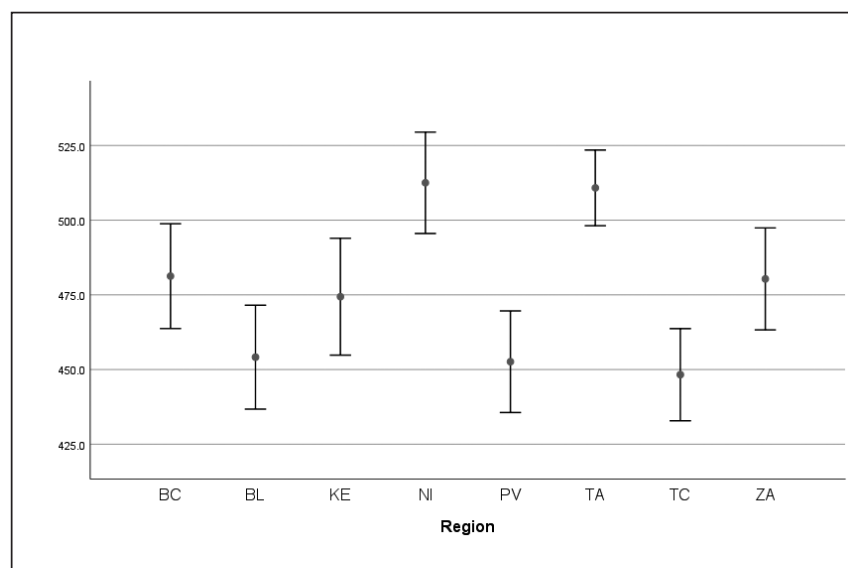

Fig. 2. Error bar plot of age-adjusted mortality rates per 100,000 persons in separate regions in Chapter II for men.

Nevertheless, it is useful to present the main table of parametric ANOVA analyses. In Table 3 there are F tests of all involved factors in selected form of model. In our case we apply also multiplication terms with purpose to test possible interaction influences. We see that all terms are significant except term sex* region and chapter* sex* region. It means that age-adjusted mortality rates are dependent on all categorical factors (chapter, sex and region). AAMR values are different in compared chapters regardless of sex and region. Also they are different in compared sexes (ignoring chapter and region) At last they are different in compared regions regardless chapter and sex. What else they are dependent also on combination of chapter by sex and chapter by region.

The interaction term tests whether the effect of one factor on the dependent variable (AAMR) is different depending on which level of the other factor is being considered.

Table 2. Result of Levene's homogeneity-of-variance test of age-adjusted mortality rates

\begin{tabular}{|c|c|c|c|}
\hline F & $\begin{array}{c}\text { Degrees } \\
\text { of freedom 1 }\end{array}$ & $\begin{array}{c}\text { Degrees } \\
\text { of freedom 2 }\end{array}$ & p-value \\
\hline 12.016 & 31 & 544 & $<0.001$ \\
\hline
\end{tabular}

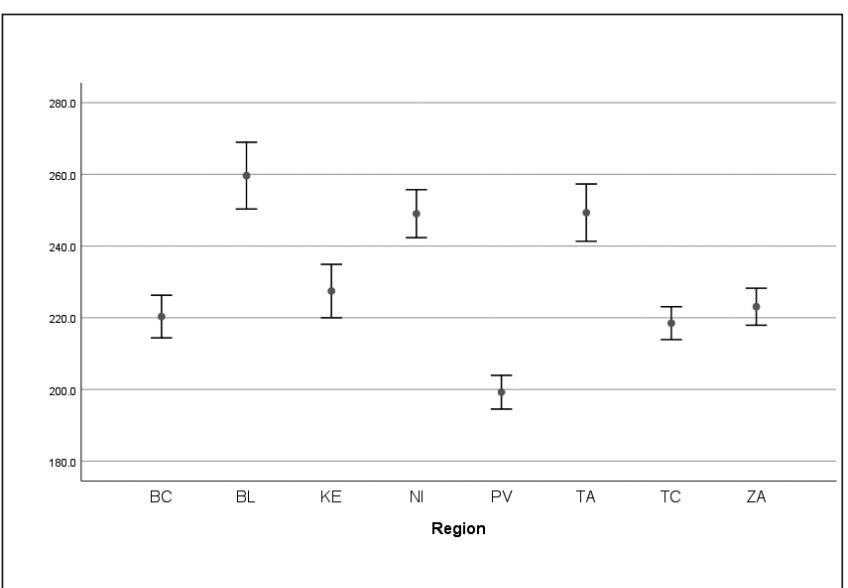

Fig. 3. Error bar plot of age-adjusted mortality rates per 100,000 persons in separate regions in Chapter II for women.

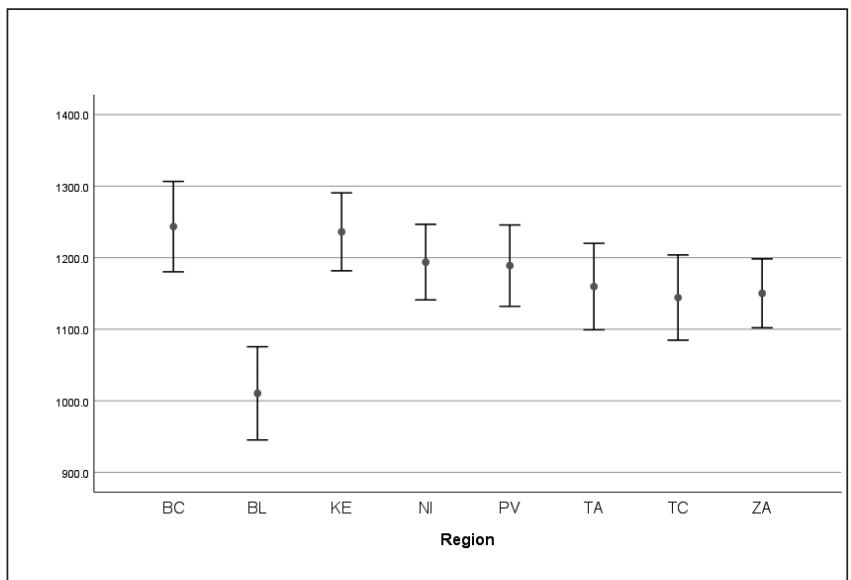

Fig. 4. Error bar plot of age-adjusted mortality rates per 100,000 persons in separate regions in Chapter IX for men.

In our case it investigates whether the effect of sex on AAMR is the same (not significant interaction) or different (significant interaction) for Chapter II and for Chapter IX.

It is symmetrical case we can also ask about the effect of chapters on AAMR for group of men and group of women.

Table 3. Basic three way ANOVA table of age-adjusted mortality rates per 100,000 persons by chapter, by sex and by region

\begin{tabular}{|l|c|c|c|c|c|}
\hline Source & $\begin{array}{c}\text { Type III } \\
\text { Sum of squares }\end{array}$ & Degrees of freedom & Mean square & F & p-value \\
\hline Corrected model & $74830385.899 a$ & 31 & 2413883.4 & 454.4 & $<0.001$ \\
\hline Intercept & 269188090.2 & 1 & 269188090.2 & 50668.5 & $<0.001$ \\
\hline Chapter & 62656416.4 & 1 & 62656416.4 & 11793.6 & $<0.001$ \\
\hline Sex & 10920276.8 & 1 & 10920276.8 & 2055.5 & $<0.001$ \\
\hline Region & 517337.0 & 7 & 73905.3 & 13.9 & $<0.001$ \\
\hline Chapter * sex & 124583.5 & 1 & 124583.5 & 23.5 & $<0.001$ \\
\hline Chapter * region & 528459.0 & 7 & 75494.1 & 14.2 & $<0.001$ \\
\hline Sex* region & 69711.2 & 7 & 9958.7 & 1.9 & 0.071 \\
\hline Chapter * sex * region & 13601.9 & 7 & 1943.1 & 0.4 & 0.922 \\
\hline Error & 2890122.6 & 544 & 5312.7 & & \\
\hline Total & 346908598.7 & 576 & & & \\
\hline Corrected total & 77720508.5 & 575 & & & \\
\hline
\end{tabular}

aR squared $=0.963$ (Adjusted R squared $=0.961$ ) 


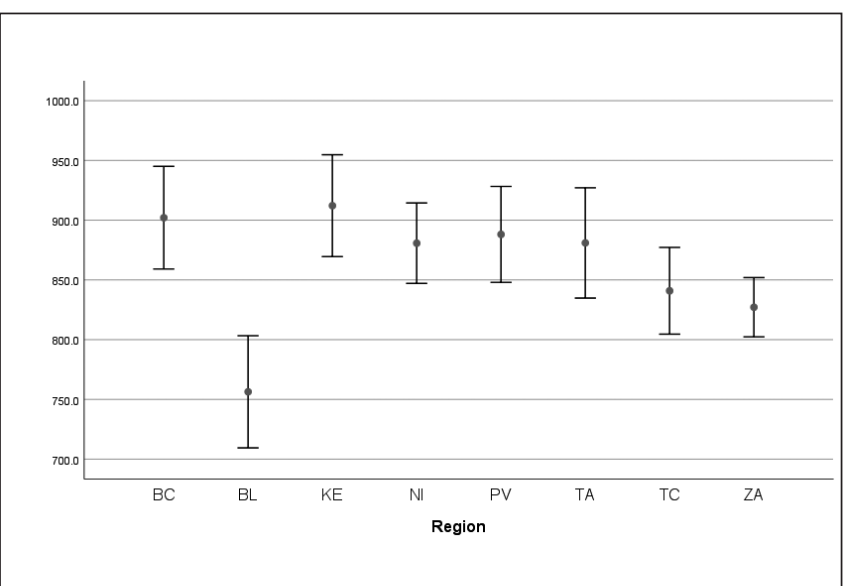

Fig. 5. Error bar plot of age-adjusted mortality rates per 100,000 persons in separate regions in Chapter IX for women.

Second significant interaction term tells us that effect of region on AAMR is dependent on chapter. Or we can say that the effect of chapter on AAMR depends on region.

From results of ANOVA (Tables 4, 5) it is clear that difference of AAMR values between chapters and sex is significant $(\mathrm{p}<0.001)$. So AAMR is larger in Chapter IX in comparison with AAMR in Chapter II. And it is larger in group of men than in group of women.

But situation is not so clear in case of regions (Table 6).

Now we want to find possible differences of age-adjusted mortality rates among Slovak regions. In spite of non-homogenous variance there is simple solution. We need to split output by both chapter and sex. Then we can find homogenous subsets of regions according to corresponding AAMR values by one-way nonparametric ANOVA Kruskal-Wallis test and its enhancement. Each row in stepwise stepdown multiple comparisons table in the sample group corresponds to a separate related sample (represented in the data by separate fields). Samples that are not statistically significantly different are grouped into samecoloured subsets; there is a separate column for each identified subset. When all samples are statistically significantly different, there is a separate subset for each sample. When none of the samples are statistically significantly different, there is a single subset. Each cell shows the sample average rank of AAMR. Significance level is 0.05 .

We see that in case of Chapter II and men three of four homogenous subsets overlap (Table 7). Only the fourth subset of Nitra and Trnava regions is distinct. These two regions are relatively and significantly worse than other regions. The best one is Trenčín region but it is not statistically better than are regions - Prešov, Bratislava and Košice.

In case of women the situation is different (Table 8). There are three distinct subsets of regions. When subset contains only one sample then of course it is not possible to compute test statistics. This is the case of the best Prešov region. Among the worst regions are Trnava, Nitra and Bratislava. Medium regions are: Trenčín, Banská Bystrica, Žilina and Košice.

On contrary in group of men and diseases of Chapter IX, Bratislava is the best region (Table 9). Other regions form two overlapping subsets. Banská Bystrica region is the worst one but is not different from regions: Košice, Nitra, Prešov, Trnava and Trenčín.

Table 4. Statistical parameters of age-adjusted mortality rates per 100,000 persons by chapter

\begin{tabular}{|l|c|c|c|c|c|c|}
\hline Chapter & N & Mean & Median & SD & Minimum & Maximum \\
\hline II & 288 & 353.8 & 338.8 & 127.50 & 179.0 & 586.8 \\
\hline IX & 288 & $1,013.4$ & 980.3 & 190.34 & 569.3 & $1,442.6$ \\
\hline Total & 576 & 683.6 & 579.1 & 367.65 & 179.0 & $1,442.6$ \\
\hline
\end{tabular}

Table 5. Statistical parameters of age-adjusted mortality rates per 100,000 persons by sex

\begin{tabular}{|l|c|c|c|c|c|c|}
\hline Sex & N & Mean & Median & SD & Minimum & Maximum \\
\hline Men & 288 & 821.3 & 667.8 & 358.70 & 385.6 & $1,442.6$ \\
\hline Women & 288 & 545.9 & 430.7 & 322.62 & 179.0 & $1,025.7$ \\
\hline Total & 576 & 683.6 & 579.1 & 367.65 & 179.0 & $1,442.6$ \\
\hline
\end{tabular}

Table 6. Statistical parameters of age-adjusted mortality rates per 100,000 persons by region

\begin{tabular}{|l|c|c|c|c|c|c|}
\hline Region & $\mathbf{N}$ & Mean & Median & SD & Minimum & Maximum \\
\hline Banská Bystrica & 72 & 711.8 & 637.5 & 401.91 & 196.7 & $1,442.6$ \\
\hline Bratislava & 72 & 620.1 & 549.3 & 299.77 & 228.1 & $1,238.3$ \\
\hline Košice & 72 & 712.5 & 625.7 & 398.37 & 212.9 & $1,390.9$ \\
\hline Nitra & 72 & 709.0 & 677.4 & 366.87 & 220.0 & $1,333.6$ \\
\hline Prešov & 72 & 682.2 & 617.3 & 391.57 & 179.0 & $1,363.1$ \\
\hline Trnava & 72 & 700.2 & 632.9 & 358.10 & 225.6 & $1,337.0$ \\
\hline Trenčín & 72 & 663.0 & 608.3 & 365.36 & 201.6 & $1,331.0$ \\
\hline Žilina & 72 & 670.2 & 634.1 & 357.25 & 199.9 & $1,381.9$ \\
\hline Total & 576 & 683.6 & 579.1 & 367.65 & 179.0 & $1,442.6$ \\
\hline
\end{tabular}


Also in group of women Bratislava is the best region in AAMR values caused by diseases of Chapter IX (Table 10). The worst region is Košice together with regions: Banská Bystrica, Prešov, Nitra, Trnava and Trenčín.

Now we could finish but what if there are significant trends in AAMR values during analysed time interval 1996-2013? And as it will be shown it is the fact. It can be proved by correlation and regression analyses. We used both classic Pearson and robust Spearman correlation coefficients of bivariate correlations between AAMR values and time by chapter, by sex and by region. So we have got $32(2 \times 2 \times 8)$ correlation coefficients and also 32 corresponding regression equations.

We present here only Spearman correlation coefficients of time dependence of AAMR values. Sometimes it is called Daniels test of trend (29). Classic Pearson correlation coefficients have got similar values but they are more sensitive to possible nonlinear trends (concave or convex) and jumps. Spearman correlation coefficients are in Table 11. We see that all coefficients are negative and most of them are significant. So we can say that AAMR values decrease significantly in almost all regions in both Chapters II and Chapter IX and in both sexes with exception of following

Table 7. Homogenous subsets of regions based on ageadjusted mortality rates of Chapter II and of men

\begin{tabular}{|c|c|c|c|c|c|}
\hline & \multicolumn{4}{|c|}{ Subset } \\
\hline & & 1 & 2 & 3 & 4 \\
\hline \multirow{8}{*}{ Region } & $\mathrm{TC}$ & 41.333 & & & \\
\hline & PV & 48.167 & 48.167 & & \\
\hline & $\mathrm{BL}$ & 49.444 & 49.444 & 49.444 & \\
\hline & KE & 70.889 & 70.889 & 70.889 & \\
\hline & $B C$ & & 76.222 & 76.222 & \\
\hline & $Z A$ & & & 76.833 & \\
\hline & $\mathrm{NI}$ & & & & 107.778 \\
\hline & $\mathrm{TA}$ & & & & 109.333 \\
\hline \multicolumn{2}{|c|}{ Test statistic } & 4.746 & 7.280 & 6.154 & 0.025 \\
\hline \multicolumn{2}{|c|}{ Adjusted $p$-value } & 0.346 & 0.123 & 0.198 & 1.000 \\
\hline
\end{tabular}

Table 8. Homogenous subsets of regions based on ageadjusted mortality rates of Chapter II and of women

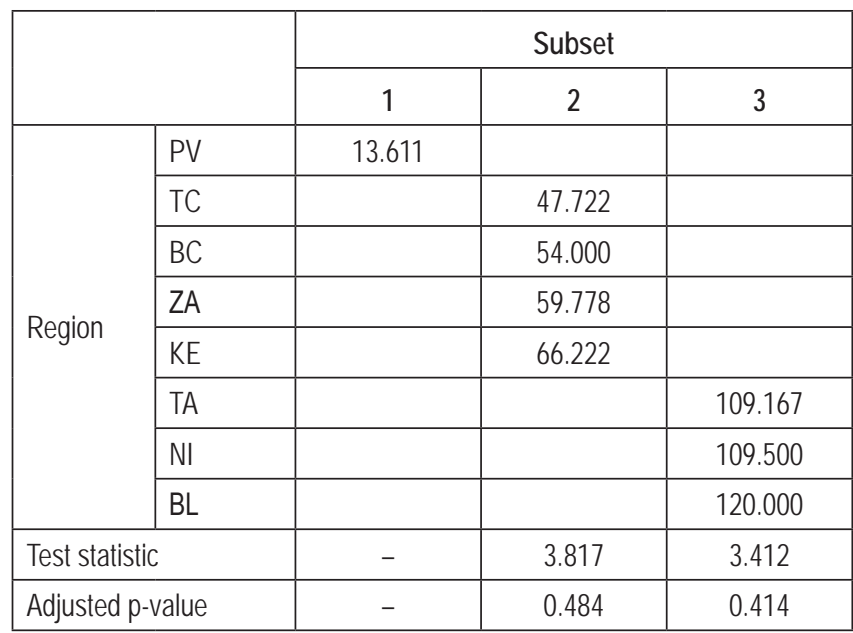

five cases of stagnation: in Chapter II in group of women there are four regions: Košice, Nitra, Trenčín and Žilina, in Chapter IX in group of women there is Žilina region.

Also we can test equality of regression slopes of men in comparison with women. It can be done easily by interaction term in ANCOVA model. There is not enough space to present all results. So we present only Figures 6-8 of AAMR line plots with corresponding linear trends for both sexes. In parenthesis there are results of ANCOVA test of regression slopes equality between men and women. If test is significant $(p<0.05)$ then slopes are different. In all graphs upper line plots represent AAMR values in group of men. The lower ones belong to group of women.

Let us start with Chapter II. There are not significant differences in regression slopes between AAMR values of men vs AAMR values of women in case of three - Banská Bystrica, Bratislava and Trnava. On the opposite there are significant differences in regions: Košice (Fig. 6, $p<0.001$ ), Nitra $(\mathrm{p}<0.01)$ ), Prešov (Fig. $7, \mathrm{p}<0.01)$, Trenčín $(\mathrm{p}<0.01)$ and Žilina $(\mathrm{p}<0.01)$. All significant differences are caused by larger regression slopes in group of men in comparison with regression slopes in group of women. Either AAMR values decline significantly but with different rates in both

Table 9. Homogenous subsets of regions based on ageadjusted mortality rates of Chapter IX and of men

\begin{tabular}{|l|l|c|c|c|}
\hline \multicolumn{2}{|c|}{} & \multicolumn{3}{c|}{ Subset } \\
\cline { 3 - 5 } \multicolumn{1}{|c|}{} & BL & 28.778 & 2 & 3 \\
\hline \multirow{5}{*}{ Region } & ZA & & 62.889 & \\
\cline { 2 - 5 } & TC & & 65.056 & 65.056 \\
\cline { 2 - 5 } & TA & & 70.389 & 70.389 \\
\cline { 2 - 5 } & PV & & 79.222 & 79.222 \\
\cline { 2 - 5 } & NI & & 80.833 & 80.833 \\
\cline { 2 - 5 } & KE & & 95.333 & 95.333 \\
\cline { 2 - 5 } & BC & & & 97.500 \\
\hline Test statistic & & - & 9.219 & 10.036 \\
\hline Adjusted p-value & - & 0.132 & 0.098 \\
\hline
\end{tabular}

Table 10. Homogenous subsets of regions based on ageadjusted mortality rates of Chapter IX and of women

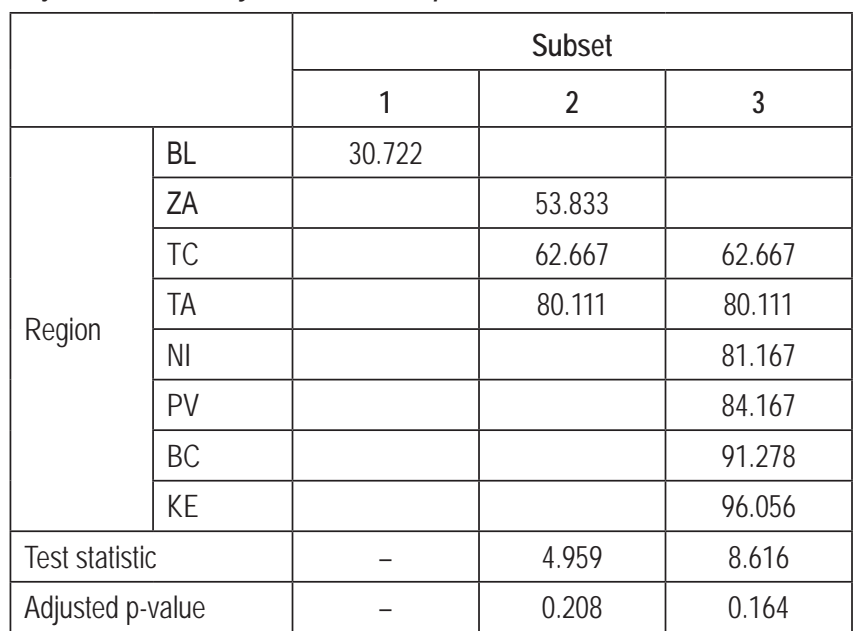


Table 11. Spearman correlation coefficients among ageadjusted mortality rates and time by Slovak regions and by sex

\begin{tabular}{|c|c|c|c|c|}
\hline & \multicolumn{2}{|c|}{ Chapter II } & \multicolumn{2}{|c|}{ Chapter IX } \\
\hline Region & Men & Women & Men & Women \\
\hline$B C$ & $-0.573^{*}$ & $-0.492^{*}$ & $-0.752^{\star *}$ & $-0.814^{* * *}$ \\
\hline $\mathrm{BL}$ & $-0.728^{* * *}$ & $-0.682^{* *}$ & $-0.967^{* * *}$ & $-0.950^{* * *}$ \\
\hline KE & $-0.866^{* * *}$ & -0.298 & $-0.917^{* * *}$ & $-0.955^{\star * *}$ \\
\hline $\mathrm{NI}$ & $-0.740^{* \star *}$ & -0.463 & $-0.847^{\star * *}$ & $-0.849^{* * *}$ \\
\hline PV & $-0.641^{* *}$ & $-0.674^{* *}$ & $-0.936^{* * *}$ & $-0.920^{* * *}$ \\
\hline TA & $-0.474^{*}$ & $-0.616^{* *}$ & $-0.915^{\star \star *}$ & $-0.934^{* * *}$ \\
\hline TC & $-0.730^{* * *}$ & -0.143 & $-0.870^{* * *}$ & $-0.901^{* * *}$ \\
\hline$Z A$ & $-0.668^{* *}$ & -0.079 & $-0.653^{* *}$ & -0.455 \\
\hline
\end{tabular}

${ }^{*} \mathrm{p}<0.05,{ }^{* *} \mathrm{p}<0.01,{ }^{* * *} \mathrm{p}<0.001$

groups (Prešov region) (Fig. 7) or AAMR values decline only in group of men and stagnate in group of women (case of regions: Košice (Fig. 6), Nitra, Trenčín and Žilina).

The results are different in Chapter IX. There are not significant differences in regression slopes between AAMR values of men vs.

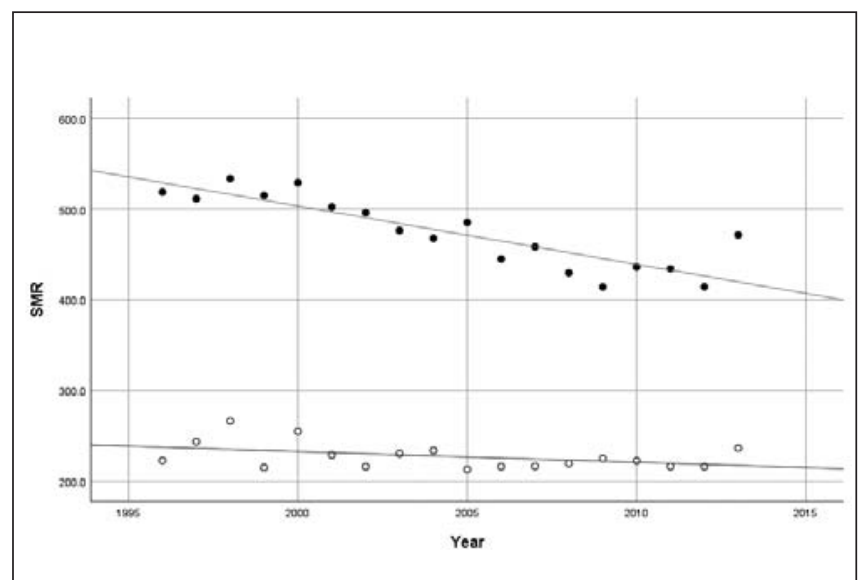

Fig. 6. Linear trends of age-adjusted mortality rates per 100,000 persons of Chapter II for men (upper line) and for women (lower line) in Košice region $(p<0.001)$.

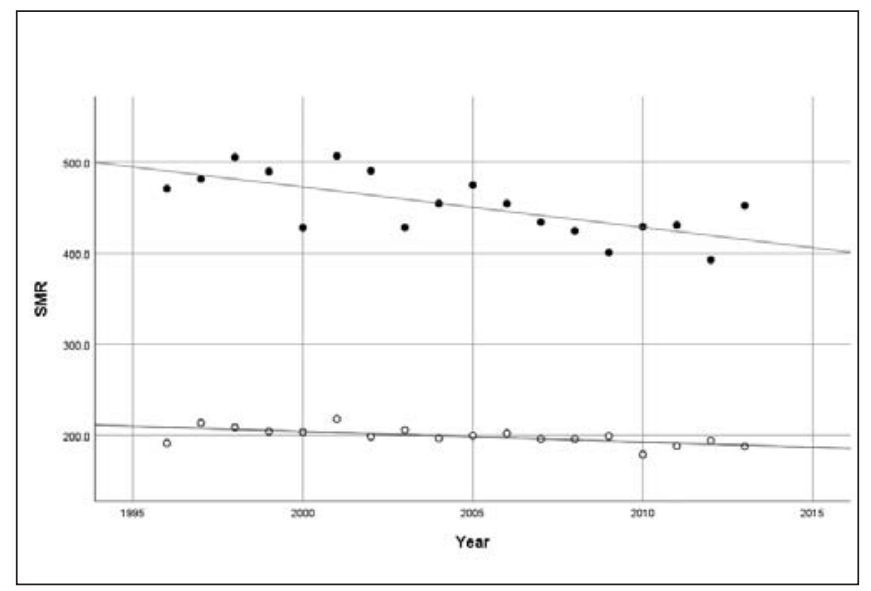

Fig. 7. Linear trends of age-adjusted mortality rates per 100,000 persons of Chapter II for men (upper line) and for women (lower line) in Prešov region $(p=0.010)$.

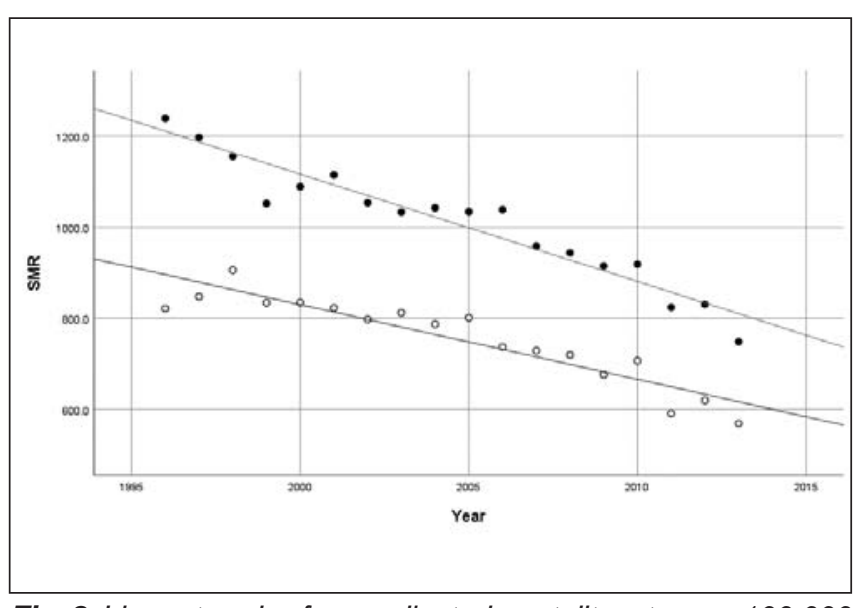

Fig. 8. Linear trends of age-adjusted mortality rates per 100,000 persons of Chapter IX for men (upper line) and for women (lower line) in Bratislava region $(p=0.005)$.

AAMR values of women in case of five regions - Banská Bystrica, Košice, Trnava, Nitra and Žilina. There are significant differences in three regions: Bratislava (Fig. 8, p<0.01), Prešov $(\mathrm{p}<0.05)$ and Trenčín $(p<0.05)$. In these regions AAMR values decline significantly but with different slopes between men and women.

\section{DISCUSSION}

We wanted to find some statistical aspects including possible trends of age-adjusted mortality rates per 100,000 persons of standard EU population in relation with available demographic factors (Chapter II and Chapter IX of International Statistical Classification of Diseases, sex, region and calendar year of death) during 1996-2013 in Slovak regions.

Our study shows significant differences of age-adjusted mortality rates between men and women $(\mathrm{p}<0.001)$. We found significant difference of age-adjusted mortality rates between Chapter II and Chapter IX $(\mathrm{p}<0.001)$. Two regions - Nitra and Trnava are worst and different from all other regions in case of Chapter II and group of men $(\mathrm{p}<0.001)$. In group of women three regions - Nitra, Trnava and Bratislava are worst and different $(\mathrm{p}<0.001)$. On contrary in group of men and Chapter IX the region Bratislava is the best and different one $(p<0.001)$. The same is valid for Chapter IX and group of women.

Values of age-adjusted mortality rates decline significantly in most of regions for both sexes with exception of stagnation in four regions in group of women in Chapter II (Košice, Nitra, Trenčín and Žilina) and one region in Chapter IX also in group of women (Žilina). In Chapter II there are not significant differences in regression slopes between AAMR values of men vs AAMR values of women in case of two regions - Bratislava and Trnava. On the opposite there are significant differences in regions: Košice $(p<0.001)$, Nitra $(p<0.01)$, Prešov $(p<0.01)$, Trenčín $(\mathrm{p}<0.01)$ and Žilina $(\mathrm{p}<0.01)$. Test value in case of Banská Bystrica is on the boundary of significance. All significant differences are caused by larger regression slopes in group of men in comparison with regression slopes in group of women. The results are different in Chapter IX. There are not significant differences in regression slopes between AAMR values of men 
vs AAMR values of women in case of three regions - Banská Bystrica, Košice and Trnava. There are significant differences in three regions: Bratislava $(p<0.01)$, Prešov $(p<0.05)$ and Trenčín $(p<0.05)$. In these regions AAMR values decline significantly but with different slopes between men and women. On the boundary of significance are two regions - Nitra and Žilina.

\section{CONCLUSIONS}

We have got some results of age-adjusted mortality rates in Slovak regions in most frequent causes of death (Chapter II and Chapter IX). Studies at the level of population are greatly required by health policy planners but we are still fighting with the unavailability of data of socioeconomic characteristics (e.g. occupational status, income level, living condition). Similarly, specific data on health behaviours such as smoking, tobacco consumption, physician utilisation, drug utilisation, etc. The regional distribution of the population also has implications for health and healthcare. Since population is older, chronic disease dominate, and raises a need of higher levels of health care resources. The new policy will need to increase the level of care to meet demand.

\section{Acknowledgements}

The work was supported by the VEGA Project No. 1/0993/15 "Genetic aspects in ethiology of dilated cardiomyopathy".

We want to thank Slovak National Center of Health Informatics which offered us kindly dataset of individual victims of deaths in Slovakia during 1996-2013.

\section{Conflict of Interests}

None declared

\section{REFERENCES}

1. Valkonen T. Socio-economic mortality differences in Europe. Hague: Netherlands Interdisciplinary Demographic Institute; 1993.

2. Markides KS, Black SA. Race, ethnicity, and aging: the impact of inequality. In: Binstock RH, George LK, editors. Handbook of aging and the social sciences. San Diego: Academic Press; 1996. p. 153-70.

3. Davey Smith G, Gunnell D, Ben-Shlomo Y. Life-course approaches to socio-economic differentials in cause-specific mortality. In: Leon DA, Walt G, editors. Poverty, inequality and health: an international perspective. Oxford: Oxford University Press; 2001. p. 88-123.

4. Hummer RA, Rogers RG, Eberstein IW. Sociodemographic differentials in adult mortality: a review of analytic approaches. Popul Dev Rev. 1998;24(3):553-78.

5. Kunst AE. Cross-national comparisons of socioeconomic differences in mortality. Rotterdam: Erasmus University; 1997.

6. Verbrugge LM. The Twain meet: empirical explanations of sex differences in health and mortality. J Health Soc Behav. 1989;30(3):282-304.

7. Arber S, Ginn J. Gender and inequalities in health in later life. Soc Sci Med. 1993;36(1):33-46.

8. Christensen K. Why do we age differently? Copenhagen: Gyldendal; 2001. (In Danish.)

9. Liang J, Bennett J, Krause N, Kobayashi E, Kim H, Brown JW, et al. Old age mortality in Japan: does the socioeconomic gradient interact with gender and age? J Gerontol B Psychol Sci Soc Sci. 2002; 57(5):S294-307.
10. Goldman N. Mortality differentials: selection and causation. In: Smelser NJ, Baltes PB. International encyclopedia of the social and behavioral sciences. Amsterdam: Elsevier; 2001. p. 1068-70.

11. Klein T. Social determinants of active life expectancy. Z Soziol. 1999;28(6):448-64. (In German.)

12. Oakes JM, Rossi PH. The Measurement of SES in health research: current practice and steps towards a new approach. Soc Sci Med. 2003;56(4):76984.

13. Delb es C, Gaymu J. The Shock of the widowhood at the edge of senescence: male and female survivals. Population. 2002;57(6):879-910. (In French.)

14. Luy M, Di Giulio P. The influence of behaviors and lifestyles on the mortality differences of the sexes. In: Gärtner K, Grunheid E, Wiesbaden LM, editors. Life styles, life stages, quality of life - interdisciplinary analyzes of health and mortality from the life expectancy survey. VS-Verlag; 2005. p. 365-92. (In German.)

15. Bassuk SS, Berkman LF, Amick BC. Socioeconomic status and mortality among the elderly: findings from Four US Communities. Am J Epidemiol. 2002;155(6):520-33.

16. Lampert T. Socioeconomic inequality and health in the higher age - age and gender - specific differences. In: Backes GM, Clemens W, editors. Living conditions in old age: social conditions and limits. Opladen, Leske und Budrich; 2000. p. 159-85. (In German.)

17. Beckett M. Converging health inequalities in later life - an artifact of mortality selection. J Health Soc Behav. 2000;41(1):106-19.

18. Kunst AE, Wolleswinkel-van den Bosch JH, Mackenbach JP. Medical demography in the Netherlands: recent advances, future challenges. In: van Wissen LJG, Dykstra PA, editors. Population issues: an interdisciplinary focus. New York: Kluwer Academic / Plenum Publishers; 1999. p. 187-228.

19. Feldman JJ, Makuc DM, Kleinman JC, Cornoni-Huntley J. National trends in the educational differentials in mortality. Am J Epidemiol. 1989;129(5):919-33.

20. Preston SH, Elo IT. Are educational differences in adult mortality increasing in the United States? J Aging Health. 1995;7(4):476-96.

21. Valkonen T. Life expectancy and adult mortality in industrialized countries. In: Smelser NJ, Baltes PB. International encyclopedia of the social and behavioral sciences. Amsterdam: Elsevier; 2001. p. 8822-7.

22. Jungbauer-Gans M, Schneider W. Health. In: Allmendinger J, LudwigMayerhofer W. Sociology of the social state: social foundations, historical contexts and current development tendencies. Weinheim: Juventa; 2000. (In German.)

23. Lauderdale DS. Education and survival: birth cohort, period, and age effects. Demography. 2001;38(4):551-61.

24. Smith JP, Kington RS. Race, socioeconomic status and health in late life. In: Martin LG, Soldo BJ, editors. Racial and ethnic differences in the health of older Americans. Washington: National Academies Press; 1997. p. $105-62$.

25. OECD regions at a glance 2016 [Internet]. Paris: OECD; 2016 [cited 2016 Dec 7]. Available from: http://www.oecd-ilibrary.org/governance/ oecd-regions-at-a-glance-2016_reg_glance-2016-en.

26. Xu J, Murphy SL, Kochanek KD, Bastian BA. Deaths: final data for 2013. Natl Vital Stat Rep. 2016 Feb 16;64(2):1-119.

27. Fleiss JL, Levin B, Paik MC. Statistical methods for rates and proportions. 3rd ed. Hoboken: J. Wiley; 2003.

28. Huitema BE. The analysis of covariance and alternatives: statistical methods for experiments, quasi-experiments, and single-case studies. 2nd ed. Hoboken: Wiley; 2011.

29. Gibbons JD, Chakraborti S. Nonparametric statistical inference. 5th ed. Boca Raton: Taylor \& Francis; 2011.

Received January 26, 2017 Accepted in revised form December 19, 2017 